\title{
ECONOMIC AND ORGANIZATIONAL PRECONDITIONS FOR THE DEVELOPMENT OF AGENCY RELATIONS IN A CRISIS PERIOD
}

\author{
Sergey Kivalov ${ }^{1}$, Olha Kibik ${ }^{2}$
}

\begin{abstract}
The purpose of the article is the research of economic-legal and organizational principles of problem solution of economic agents' functioning and implementation of activities within the system of anti-crisis measures in order to ensure the effective functioning of the country's economic system. Crisis phenomena change the living tendencies of any economic agent. The purpose of each economic agent is to create sufficient capacity for functioning and development in favourable and especially in crisis conditions. In order to ensure the effective development of a business entity as an economic agent, the main condition is the maximization of its value by increasing the investment attractiveness and level of competitiveness in the domestic and foreign markets. Formation of this condition is a prerequisite for survival in a crisis situation and development ensuring in favourable circumstances. The elements of anti-crisis management should be correctly integrated into the general policy of the management system of economic agents at the microeconomic and macroeconomic level. The subject of the study is the functioning of economic agents in a crisis. Research methodology. The study is based on the use of general scientific and specialscientific methods of scientific knowledge. The dialectical method allowed investigating the definition of agency relations. The method of system analysis was used to study the principles and economic and legal preconditions of the functioning of the anti-crisis management systems. The system-structural method helped to study basic precrisis measures to develop crisis-response potential of maritime agency service. Practical implications. The article considers the mechanism of economic and legal provision of anti-crisis management drawing on the example of maritime agents. The most significant components of the transaction costs of the principal are determined. Value/originality. The role of maritime agents' associations has been identified. The necessity and preconditions for accelerating the adaptation of the world experience of the functioning of self-regulated organizations in the field of the maritime agency, in order to improve the state of the majority of economic entities, is proved. The development of cluster forms of the organization of interaction of different participants in maritime activity was determined as a positive trend. The promising area for further research is the formation of a model of responsible relationships between economic agents of different levels in order to achieve optimal results of realization of individual and social economic interests at key stages of the life cycle of the economic systems functioning.
\end{abstract}

Key words: agent, agency relations, maritime agent, anti-crisis management.

JEL Classification: M19, K30, D23, R49

\section{Introduction}

The crisis is the functioning stage of the vast majority of modern economic systems of different levels. Currently, the crisis is the development phase of any complex system. The World Bank has worsened the forecast of the world economic growth in 2019 from $3.0 \%$ to $2.9 \%$ due to the increased risks of adverse factors. In the future, it can only reach a level of $2.8 \%$ (Worldbank, 2019). Such indicators simultaneously are consequences and prerequisites for reducing the investment activity of economic agents of different levels. Accordingly, many world experts predict a global economic crisis, which will definitely affect the performance indicators of the majority of countries. Crisis phenomena of a global level are particularly threatening for developing countries in the context of internal conflicts of the political, economic, and social nature. Ukraine is one of such countries, where the World Bank predicted GDP growth by $2.9 \%$.

Characteristics of crisis phenomena are conditioned by the state of the economic system itself and the influence of the environmental factors. Taking into account the peculiarities of origin, existence, and

\footnotetext{
Corresponding author:

${ }^{1}$ National University “Odessa Law Academy”, Ukraine.

${ }^{2}$ National University “Odessa Law Academy”, Ukraine.

E-mail: kibik@ukr.net
} 
overcoming of crisis phenomena is a prerequisite for the survival and further development of economic agents.

At this time, there are different approaches to determining the essence of agents, the peculiarities of their functioning, the status of organizational and legal provision of agency activities, the role of agents in economic activity.

Economic agents, on the one hand, consider participants in economic processes that independently accept and implement economic decisions in the processes of production, distribution, exchange, and consumption. Accordingly, the main economic agents are households, business entities, and the state. The role and economic power of each agent are determined by the factors of production, which belong to him.

On the other hand, the agent is an entity that carries out economic activities in accordance with the rules determined by the principal. Agency relations develop in various spheres of life of modern society. There is an opinion that public administration is a system of agency relations between society and public authorities. Today the activities of business management agents, called institutional management agents, become more active. The problem of improving agency relations in corporate governance becomes relevant to corporate relations development. The development of modern macroeconomic systems is impossible without the presence of the developed network of agents, who have various functions and carry out various activities, in particular, business processes. International maritime transport is a sphere of modern economic activity, which is important for the development of world economic relations. The maritime industry has overcome a significant number of crises of various scales, timelines, consequences, etc. In addition, the majority of maritime businesses undergo a difficult period at this time. Nevertheless, over a long period, there is an increase in volumes of sea transportation. Maritime transport is a complex mechanism, an important component of which is the activity of maritime agents.

The development of spheres and scales of agency relations and activation of agency activities are definitely positive trends. However, amid the economic crisis, the level of development of agency relations and agency activities can have a positive and negative impact on the functioning of economic systems of different levels.

The basics of crisis management were the object of scientists' research in the field of public administration, economics, law, etc.

On that particular crisis periods, the problem of agency relations is one on the rise among the scientists. So the first serious attempt of scientists to investigate the influence of the state of agency relations on the development of economic systems was made in crisis times of 1928. Events of the Great Depression period stimulated the development of the theory of agency relations. So the scientists A. Berle and G. Means defined the role of agency relations in ensuring the efficiency of the corporations' functioning (Berle, Means, 1932).

O. Golovchenko, I. Malyi, L. Yemelianenko, I. Radionova, V. Shariy made a significant contribution to the study of crisis phenomena. However, it should be noted that crisis management aspects are separately investigated for enterprises, region or industry.

Most crises are caused by conflict situations. The operation of economic agents and agency activities is not an exception.

The theoretical basis of the conflicts of principals and agents is highlighted in the researches of such foreign scholars as M. Jensen, W. Meckling, M. Yermovsky, C. Chach.

The works of the such Ukrainian scientists as O. Kotlubay (Kotlubay, 2008), N. Primachova (Primachova, 2014), V. Zhikhareva (Zhikhareva, 2012), and others are devoted to the study of the process of formation anti-crisis management system on sea transport for strengthening the potential of development of enterprises of the maritime complex.

Scientists from other countries P. Alderton (Alderton, 1998), Costas Th. Grammenos (Grammenos, 2002), P. Kieran (Kieran, 2003), S. Kumar, J. Hoffman (Kumar, 2002), M. Stopford (Stopford, 1988) also paid attention to the development anti-crisis management potential.

A special place in the system of agency activities for maritime states is the maritime agency service whose problems were studied by S. Bonyar, V. Vygovsky, O. Kotlubay, A. Kudyukin, L. Nikolayeva, P. Petrov.

Despite the presence of numerous scientific works, the problems of economic, legal, and organizational maintenance of effective functioning of agents in crisis conditions, which should be studied within the framework of the theory of agency relations, remain unsolved.

The purpose of the article is the research of problemsolving principles of business entities as economic agents functioning and implementation of activities within the system of anti-crisis measures in order to ensure the effective functioning of the country's economic system.

\section{Presentation of the main material}

The development has a cyclical nature, which causes periodic advent of the crisis. Nowadays the list of crises is significant. Thus, in theory, social crises are divided into economic, political, religious-spiritual, monetary, financial, demographic, environmental, managerial, etc. However, in practice, such crises mainly arise, which have signs of different types of crises, which makes them even more threatening for the future existence of the entity. Crises need to be foreseen. Not only crisis causes but also their various consequences are important. Experience has shown that getting out of the crisis is associated with negative and sometimes positive effects. On the basis of the absence or ineffective anti-crisis management, the transition of the agent's economic system to the state of 
the new crisis is likely, which may be even more profound and prolonged. Crises can cause a chain reaction. The above is especially relevant for the modern stage of the dynamic development of economic agents.

All economic agents aim at rationality but the possibilities of its implementation are quite limited by various factors. Therefore, in order to ensure effective functioning and sustainable development, each economic entity has to use anti-crisis management tools.

Anti-crisis management as a concept is actively used in recent decades. In our time, anti-crisis management is a necessary component of governance in general. The purpose of crisis management is to increase the level of efficiency of the potential usage of an economic agent under the condition of rhythmic functioning due to timely avoidance, prevention, and elimination of risks.

The development and implementation of the measures to prevent and to get out from crisis for economic agents, in particular system one, should be based on the national and global socio-economic systems and legal laws functioning.

An obstacle to overcome crisis phenomena for the economic agent is the lack of an effective development policy or if there is any - economic and legal preconditions for its effective implementation. Failure to match the interests of economic agents is a prerequisite for the emergence of conflict situations that increase the negative impact on the performance of individual agents and higher-level economic systems.

The economic agents of different levels should form the anti-crisis management systems in consideration of the following principles (Carlin, 2001), among which we consider the main such as the following:

- the principle of legality (anti-crisis management should be carried out in accordance with current legislation); - the principle of shared objectives (all measures of anticrisis management are implemented in order to achieve the goal, which should be clearly defined by the time of achievement, quantitative and qualitative results);

- the principle of depth (the implementation of anti-crisis management measures is aimed at eliminating external symptoms of the crisis, identifying and, if possible, neutralizing the factors that predetermined the crisis);

- the principle of effectiveness (sufficient level of effectiveness of anti-crisis management can be ensured on the basis of optimal use of the potential of all elements of the anti-crisis management system, taking into account the condition of constraints and, accordingly, optimizing the costs of financial, material, time, and other resources); - the principle of authority and responsibility (anti-crisis management should be carried out by persons who have the appropriate rights and must be responsible for their actions and their consequences);

- the principle of conformity (the system of anti-crisis management should be developed taking into account the specific conditions, features of functioning, and desired prospects for the development of an economic agent).
Within the conditions of the crisis, it is necessary to increase attention to the problems of agency relations improvement. There is a steady increase in the number of economic agents that interact with other agents of different levels and spheres of actions. In accordance with the theory of agency relations, the agent is in a relationship of subordination with the principal. Agents operate actively in the areas of foreign economic activity, maritime business, tourism, advertising, banking, insurance, investing, etc. By legal reasons, contractual and non-negotiable agency activities are distinguished. By the degree of compulsory implementation of agency activities, it can be mandatory and optional. By the legal status of the agent, universal and specialized activities are distinguished. There are professional and unprofessional agents based on the principles of implementation. Under the licensing obligation, agency activity may be such that it requires a license or not. The current trend is an active reduction of agency activities that require the necessity of licensing.

Let's consider the issue of economic and legal provision of anti-crisis management drawing on the example of the work of maritime agents, whose range of activities is significant at this time and continue to grow despite the obstacles. Entities providing maritime agency services are active participants in foreign trade activities engaged in the export of services and provide currency revenues to the state budget. At the same time, these companies create preconditions for the development of the potential of export-oriented national business structures, as the significant proportion of export goods is transported by the sea, that is, exported from seaports.

Maritime agent's service is a commercial agency. The complex of ship agency services provided by the maritime agent to the shipowners, cargo owners, and consignees is the most common in seaports.

The activities of a maritime agent are often compared to judicial practice. In the process of maritime carriage, there is a conflict of interests of the shipowner, charterer, cargo owner, stevedoring company, port administration, and other involved participants.

A port agent represents and protects the interests of his principal, that is, he performs functions similar to lawyer functions. The maritime agent deal with formalities and actions related to the vessel's arrival, stay, and departure, assists the ship's captain in establishing contacts with the administration of the seaport and the captain's seaport service, the owner of the maritime terminal, enterprises, institutions, organizations providing specialized services, ports operators, local authorities, in the supply and vessel service organizing in the port, draw up customs documents and cargo documents, etc. (Grammenos, 2002). According to the estimates of the international nonprofit organization FONASBA, which is an association of ship brokers and agents, up to 150 individual operations are required to allow the vessel to enter the port, to carry out cargo operations, to depart and to continue with the next port, many of which 
must be completed within a limited time (FONASBA). Additional time of presence of the vessel in the port of call related to the observance of the requirements of national legislation, the organization of transportation, etc., causes a significant increase in vessel costs and failure to comply with the shipping time. There are no two identical ports in the world, which causes differences in the ships' service. Thus, the skilled work of maritime agents is a prerequisite for the effective operation of the shipowners, port operators, and a wide range of end consumers of transport enterprises. The maritime agent carries out its activities in accordance with the usual practice of maritime agency. In accordance with the customs and practice of the maritime international agency, the conclusion of maritime agency agreements is mainly carried out by telex messaging of the maritime agent by the shipowner to or via e-mail. In such notification, only the characteristics of the vessel, which are necessary for the payment of channel, pilotage, port, and other mandatory fees, are given. The mentioned form of the contract conclusion of maritime agency does not contradict the norms of the current legislation of the majority of the countries, in particular, Ukraine. That is, it is possible to conclude economic contracts in a simplified way by exchanging electronic letters, faxograms, etc. The contract is considered to be concluded upon the condition of reaching an agreement on the essential terms of the contract. The essential conditions of the agency agreement, in accordance with the current legislation of most states, is the scope, nature, and procedure for the agent to perform intermediary services, the rights and obligations of the parties, the conditions and amount of remuneration to the commercial agent, the validity of the contract, sanctions in case of violation of the terms of the contract, others necessary conditions specified by the parties (Lokotey, 2017).

The existence of the contract is not a guarantee of the absence of relations problems between the maritime agent and the principal. First of all, agents try to maximize the results of the implementation of their own interests, sometimes giving way to the interests of the client. Such agent's behaviour is possible provided that there are problems in the legal environment, in particular, in the sphere of regulation of competitive relations, the formation of information resources, organization of financial flows, etc. If there is an information advantage, the agent may be tempted to adjust his behaviour to increase his own profit. As an expert, the international organization FONASBA has developed a set of standards that help to protect the interests of principals (Fonasba). Compliance with standards is a prerequisite for the optimal realization of economic interests and the maritime agents themselves.

In the view of scientists and experts (Bonyar, 2016; Kibik, 2018), the main factors that slightly slow down the development of maritime agents markets in the developing countries, in particular in Ukraine, are:
- the amount and length of coastal control procedures that compels shipowners and maritime agents to use corruption-based dispute settlement schemes with numerous representatives of the authorities;

- problems of non-compliance by maritime agents with the norms of professional ethics. In accordance with the UNCTAD Minimum Standards (adopted in 1988), the responsibility of maritime agents is to carry out their activities in good faith, which implies fairness, impartiality, and due diligence on the part of the maritime agent in order to exclude fraudulent practices (UNCTAD, 1988). However, each principal and each agent have their own economic interest. Therefore, not all maritime agents working in the world seaports adhere to the provisions of the Code of Professional Conduct. Despite the increase in the intensity of the competition, there are many examples of various methods of misleading their principals used by maritime agents, which adversely affects the state of the principals and, subsequently, the agents themselves;

- arrangement of "special" conditions of cooperation between the port administration and the maritime agent, in which the agent takes priority over the main interests of the port administration, which adversely affects the performance of duties towards the principal; - the existence of local monopolies and arrangements between private owners of maritime terminals and business entities providing services to the maritime agency. Such violations of the principles of market activity do not comply with the provisions of the competition law;

- peculiarities of the activities of maritime agents on terms of deferred financing, which increases the degree of financial risks, especially in the context of limited own financial resources, high cost and complexity of obtaining the resources involved in crisis phenomena.

A network of agency companies in the maritime business has been established in Ukraine. Foreign companies such as ZIM, SEALAND, CMA CGM, MAYERSK, Chinese "COSCO", NIEDDELLOID, LLOYD TRIESTINO, EVERGREEN, CMN, etc. took up leading positions in the Ukrainian ports in different times. In addition, such companies as BSGSA "Inflot", SMT "Yuzhny Ltd.", Atis Ltd., Skif Shipping LLC, Odemara LLC, Pacific Metropolitan Ltd., Polaris Ltd, Interbroker LLC, LLC "REM Shipping", Diamant Ltd., Novik Ltd., and others operate in the market.

Recently, most of the national companies have considerably worsened their performance. Some of the maritime agents may be described as being in a crisis state. Some companies generally left the market without realizing a timely set of anti-crisis measures.

Agents associations that assess and control the companies' professional level and provide a representation of the interests of agency companies at the international level are of particular importance for the prevention of crisis phenomena through the protection of interests. In Ukraine, in the field of ship's agency service, these functions are performed by the 
Association of Maritime Agencies of Ukraine. At the international level, the organization FONASBA plays an important role. According to world practice, an effective means for the prevention and resolution of crisis phenomena is the vigorous activity of a self-regulated organization. In the world practice, the state delegates its functions to self-regulating professional organizations in order to improve the market situation, overcome corruption, reduce the costs of public administration, etc. Ukraine has made the first steps in this direction. In order to improve the status of the majority of business entities, the process of world-wide experience of selfregulated organizations adapting, in particular, in the field of ship's agency service, should be accelerated.

The current trend is the development of cluster forms of organizing the interaction of different participants in business activities. In the world practice of maritime business, there has been observed the maritime clusters development at the basis of the ports, whose active agents are agency companies.

Rational behaviour of economic entities means that their purpose is to obtain the maximum end-result that can be achieved on the basis that they receive maximum income at a minimal cost. The maritime agent is not an exception who calculates his own remuneration and notes it on a disbursing account that the principal (shipowner) pays within a noticeable period. It is common practice that under favourable conditions, the remuneration of the maritime agent significantly exceeds its costs associated with the provision of maritime agency services. The fee for the agent's loyalty to the principal is included in this interest. In crisis times, loyalty fees can sometimes go down significantly, which can lead to conflict situations.

The agent's expenses of the principal arise as a result of the principal's transfer to the agent of financial resources to obtain certain products. The principal also bears other costs, in particular, to control the activities of the agent. Due to certain actions of the agent to achieve the goals, the principal can suffer losses (Jensen, Meckling, 1976).

In the present context, the provision of agency services involves the formation of principal transaction costs, the overestimation of which may cause the formation of crisis phenomena. In general, the amount of transaction costs can be calculated using the formula:

$R_{\text {tr }}=R_{\text {inf orm }}+R_{o b}+R_{m}+R_{\text {inf } l}+R_{c d m}+R_{\text {contr }}+R_{\text {self-lim }}+R_{\text {other }}$, where $R_{\text {inform }}$ - information costs, which are determined by the need of information search, very poor volumes, and the level of information quality. As a result of the increased role and increase in the information resources cost, an increase in the amount of this component of transaction costs has recently been observed. Under the condition of the increasing level of dynamism, the complexity of economic activity and, accordingly, the expansion of the relations between agents with principals, other agents, and economic agents, the level of information restriction for agents is reduced. Economic agents need more volumes of relevant information. Information is, on the one hand, more technically perfect, on the other hand, information is a more expensive resource. However, saving on costs associated with the acquisition or production of information resources is ineffective. In the sphere of ship's agency service, information costs represent a significant proportion of production costs for the agent and the principal in the form of transaction costs;

$\mathrm{R}_{\mathrm{ob}}$ - the costs of opportunistic behaviour of one or both (all) economic agents that violate the agreements, rules, norms in their own interests to the detriment of other economic agents;

$\mathrm{R}_{\mathrm{m}}$ - measuring characteristics costs that the agents produce;

$\mathrm{R}_{\text {infl }}$ - influence costs, which involve the cost of resources due to attempts to influence the decision (behaviour) of other economic agents;

$\mathrm{R}_{\mathrm{cdm}}$ - costs of collective decision-making. The current stage is characterized by the expansion of the spheres of the adoption of coordinated (collective, team) decisions. However, the development and adoption of such solutions require additional resources costs and sometimes losses;

$\mathrm{R}_{\text {contract }}$ - contract costs associated with the need for contract preparation, legal support, negotiation, etc.;

$\mathrm{R}_{\text {control }}$ - costs of the agent's behaviour control during the contract performance and the results of contract performance;

$\mathrm{R}_{\text {self-lim }}$ - self-limited costs, related to the need to fulfil obligations and accordingly, temporary disregard of their own interests;

$\mathrm{R}_{\text {other }}$ - other costs.

The majority of the abovementioned components of the total cost can be calculated approximately, in particular, using the expert judgment method. Most accurately you can determine the third component, which is the payment size for the product, which is produced by the agent and accordingly implemented to the principal.

The maritime agent acts on behalf of the shipowner and undertakes, on the basis of an order for payment, actions on his behalf, but at the expense of the shipowner. In the majority of the developed and developing countries, remuneration rates for a maritime agent for the agent's service of the ships calling at national ports are established by agreement between the parties. From the beginning of June 2014, the practice of individual determination of a fee depending on the size and type of the vessel, the port of call; the purpose with which the vessel enters the port (for the transshipment of goods not related to cargo and (or) passenger operations, transit), availability of additional services, etc. (Table 1) (Lokotey, 2017).

The usage of such pricing approach meets the current conditions of economic activity of the agent and the principal. Given the adoption of effective price decisions from both sides, this approach contributes to 
Table 1

The range of agency fee rates in the seaports of Ukraine

\begin{tabular}{|l|c|c|}
\hline \multicolumn{1}{|c|}{ Agency services } & \multicolumn{2}{c|}{$\begin{array}{c}\text { Agency fee } \\
\text { US dollars /vessel call }\end{array}$} \\
\cline { 2 - 3 } & minimum level & maximum level \\
\hline Ship's agency service entering the port for the purpose of carrying out the operations with liquid cargoes & 22 & 4181 \\
\hline Ship's agency service entering the port for the purpose of carrying out the operations with bulk cargo & 25 & 3726 \\
\hline $\begin{array}{l}\text { Ship's agency service entering the port for the purpose of carrying out the operations with general, } \\
\text { forest, and mixed cargoes }\end{array}$ & 57 & 7736 \\
\hline $\begin{array}{l}\text { Ship's agency service entering the port for the purpose not related to the carriage of goods and (or) } \\
\text { passenger operations }\end{array}$ & 8 & 1422 \\
\hline Agency service for passenger ships and private yachts & 128 & 2289 \\
\hline Additional agency services & Percentage of the provided service \\
\hline
\end{tabular}

Source: compiled by the authors based on the data of Ministry of Infrastructure of Ukraine, Lokotey, 2017

the optimal realization of the economic interests of the principal and the agent.

Table data indicate that there are significant differences in the level of rates. In some positions, rates vary hundreds of times, due to the peculiarities of agency activities in specific ports, each of which is unique. Differences in the rates' level are also indicative for the world practice of ship's agency service. The relative share of agency costs in the goods transportation cost comes to approximately $0.1 \%$. The percentage of the cost of paying agency services in the contract for the supply of goods is approximately equal to $0.04 \%$. Despite such a relative share of the agency costs, the agent's work can determine the critical state of vessel service in the port, significant problems in organizing the next stage of transportation, respectively, the final, in particular, financial, the results of transportation of goods to the end consumer.

Working in a complex and regulated maritime sector, maritime agents have to continually evolve; first and foremost, it is about the upgrading of company employees. In order to provide a high level of service to the clients, agents must comply with the provisions of the existinglegal acts, in particular conventions, comply with numerous complex and detailed instructions, rules applicable to the activities of the maritime complex enterprises. The legal framework of the operation of entities of the maritime business activities is dynamic. Lack of familiarity, incomprehensibility and, accordingly, non-compliance with the provisions of the current documents may lead to delays, claims, financial sanctions, fines, etc.

On the other hand, the principals may also be mistaken. Agents should not be responsible for such mistakes. FONASBA actively supports the implementation of the principle "as agents only" (only as an agent) used in English law and other jurisdictions to protect maritime agents from errors or omissions of their principals. By signing contracts with the words "as agents only," the agent under all conditions of the contract acts only as a representative of the principal, reducing the risks of conflict situations and the occurrence of crisis phenomena.

Among the factors that cause the crisis in the external environment of economic agents of the micro level, in particular, the agency companies, it should be noted the negative socio-economic situation in the country, the ineffectiveness of tax and legislative systems, reducing the market capacity, reducing demand and increasing the intensity of competition, the instability of the currency market, etc. Analysing the possible crisis phenomena of Ukrainian business entities, we can say that today they are mostly the manifestations of external negative influence.

Among the factors that determine the peculiarities of the current stage of the Ukrainian ship's service agencies development, the main ones are:

- the imperfection of the anti-crisis concept of agency activity and the legislative framework of the state anticrisis management in this sphere;

- increase of competition intensity in the markets of transport products, works, and services;

- variety of forms of ownership;

- the complexity of organizational management structures; - the imperfection of the system of indirect state regulation enterprises methods that are in private ownership, etc.

Anti-crisis management of the sea complex operation of the majority of the states is carried out at the state, regional, and sectoral levels on the basis of direct and indirect methods. At the level of state-owned enterprises, anti-crisis management implies the usage of direct and indirect methods by the state. As for privateowned enterprises, the state may use indirect methods of anti-crisis management.

Anti-crisis management measures of the economic agents' activities at the state level can be in the form of development and implementation of legislative acts, the definition of targeted financial and social policies, promotion of small business, support and stimulation of innovation activity, ensuring the country's competitiveness in the world market, etc. All these measures are important for maritime agents.

For the companies involved in the ship's agency service, it is expedient to implement a set of basic pre-crisis measures to develop crisis-response potential (Kibik, 2013):

- qualitative analysis of transport services markets, in particular, agents one; 
- improvement of organizational and management structure;

- increasing the competitiveness of services, elements of resource potential, especially personnel, the company as a whole;

- analysis and optimization of financial results and indicators;

- solvency provision;

- improvement of price policy, etc.

\section{Conclusions and future research}

Crisis phenomena change the living tendencies of any economic agent. The purpose of each economic agent is to create sufficient capacity for functioning and development in favourable and especially in crisis conditions. In order to ensure the effective development of a business entity as an economic agent, the main condition is the maximization of its value by increasing the investment attractiveness and level of competitiveness in the domestic and foreign markets. Formation of this condition is a prerequisite for survival in a crisis situation and development ensuring in favourable circumstances. The elements of anti-crisis management should be correctly integrated into the general policy of the management system of economic agents at the microeconomic and macroeconomic level.

An agent in any field of activity undertakes to command principal financial resources effectively and honestly. In practice, the agent's behaviour due to different reasons may differ from the one that is most effective from the principal position. Differences can take different forms. In the world practice, depending on the sphere where agency activities are carried out, there are laws, legal norms, traditions, customs, observance and consideration of which are intended to reduce the negative effects of such a phenomenon as the "limited rationality" of the agent.

As the result of agency services provided, the principal meets the transaction costs, the size of which can significantly affect the financial and economic state of the principal, which may be a prerequisite for the crisis phenomena emergence. The promising area for further research is the formation of a model of responsible relationships between economic agents of different levels in order to achieve optimal results of realization of individual and social economic interests at key stages of the life cycle of the economic systems functioning.

\section{References:}

Alderton, P. (1998). Sea Transport: Operation and Economics. London: Tomas Reed, 226 p.

Berle, A. and Means, G. (1932). The Modern Corporation and Private Property, Macmillan, N.Y.

Bonyar, S. (2016). Integration prospects of agency industry in Ukraine in the European economic area. Scientific Journal of Kherson State University, 21(1), 68-71.

Carlin, W. and Soskice, D. (2006). Macroeconomics: imperfections, institutions, and policies. Oxford University Press.

Darkening Prospects: Global Economy to Slow to 2.9 percent in 2019 as Trade, Investment Weaken (2019). [Online], available at: http://www.worldbank.org/en/news/press-release/2019/01/08/darkening-prospectsglobal-economy-to-slow-to-29-percent-in-2019-as-trade-investment-weaken

Drazen, A. (2001). Political Economy in Macroeconomics. Cambridge; Massachusetts.

Grammenos, Costas Th. (2002). Handbook of Maritime Economics and Business. London, Hong Kong: LLP.

Jensen, M. and Meckling, W. (1976). Theory of the firm: Managerial Behavior, Agency costs and Ownership Structure. Journal of Financial Economics, 3, 305-360.

Kibik, O. and Kotlubay, V. (2013). Prerequisites for the development of crisis management in the economic system of Ukraine. Research Papers of National University "Odessa Law Academy", 13, 213-219.

Kibik, O., Khaiminova I., Kotlubay V., Redina I. and Belous E. (2018). Development potential of Ukrainian maritime enterprises. International Journal of Engineering \& Technology, 7(4.3), 461-466.

Kieran, P. (2003). World trends in Shipping and Port reforms. CPCS, Transcom.

Kumar, S. and Hoffman, J. (2002). Globalization: The Maritime Nexus. Loeb-Sullivan School, Maint Maritime Academy, Castine.

Kotlubay, A. (2008). Ukrainian merchant shipping problems and development prospects. Odessa.

Lokotey, T. (2017). Sea shipping agency operations: legal regulation, tax accounting and tax accounting. [Online], available at: https:/\%jurliga.ligazakon.net/analitycs/167198_operats-z-agentuvannya-morskikhsuden-pravove-regulyuvannya-bukhgalterskiy-ta-podatkoviy-oblk

Port Procedure. (2019). [Online], available at: https://www.fonasba.com/fonasba-initiatives/fonasba-portprocedure-survey

Primachova, N. (2014). Anti-crisis management on sea transport. Odessa.

Quality-standard. (2019). [Online], available at: https://www.fonasba.com/fonasba-initiatives/fonasba-quality-standard Stopford, M. (1988). Maritime economics. London: Harper Collins Academic.

UNCTAD (1988). Minimum Standards for Shipping Agents, Distr. GENERAL UNCTAD/ST/SHIP/13 7 September 1988. [Online], available at: https://unctad.org/en/PublicationsLibrary/unctadstship13_ru.pdf Zhyhareva, V., Kotlubay, A. and Kibik, O. (2012). Economics of Maritime Transport. Burun Knyga, Harkov. 